September 2009

\title{
Comment on the IASB Discussion Paper "Preliminary Views on Revenue Recognition in Contracts with Customers"
}

\author{
Jan Marton (Gothenburg University) and Alfred Wagenhofer (University of Graz) \\ on behalf of the European Accounting Association's \\ Financial Reporting Standards Committee ${ }^{1}$
}

The joint IASB and FASB Discussion Paper "Preliminary Views on Revenue Recognition in Contracts with Customers” from December 2008 proposes a single standard for the accounting of contracts with customers. It aims to eliminate inconsistencies in current IFRSs and US GAAP. A contract with customers consists of performance obligations, which are defined as a promise to transfer an asset (good or service) to the customer. The contract is recognized as a (net) contract asset or contract liability. Revenue is recognized when the entity satisfies a performance obligation. The key criterion is the transfer of control of the asset to the customer (rather than the entity's activities to satisfy the obligation). Measurement of the performance obligation and the contractual rights would be based on the transaction price, which is allocated to the performance obligations based on their stand-alone selling prices. A performance obligation should not be adjusted subsequently except if it is deemed onerous. The proposed revenue recognition principle is conceptually significantly different from the current rules, and it would change accounting practice particularly for construction contracts and for multi-element contracts. The preliminary views of IASB and FASB stated in the Discussion Paper contain a number of fundamental issues, on which the boards invite views from their constituencies.

In line with the EAA Financial Reporting Standards Committee's mission statement, the objective of this paper is to collate and bring to the IASB's attention research that is relevant to the deliberations and to point out research needs for an adequate way forward to the issues the IASB aims at resolving. The accounting for revenue recognition is clearly an international issue and, hence, our review includes research from all over the world. Our emphasis is on

\footnotetext{
${ }^{1}$ Other members are: Graeme Dean, University of Sydney; Lisa Evans, University of Edinburgh; Günther Gebhardt, Johann-Wolfgang-Goethe Universität (Chair); Martin Hoogendoorn, Erasmus Universiteit Rotterdam; Araceli Mora, Universidad de Valencia; Ken Peasnell, Lancaster University; Roberto Di Pietra, Università degli Studi Siena; and Frank Thinggaard, Aalborg University.
} 
research from European countries, although we note at the outset that there is relatively little European research that studies this issue. The papers we survey give a sense for the broad methodological approaches and results in the area. However, we do not claim that they represent a comprehensive list of work in this area.

Our comment is organized as follows: In the next section, we present prior research according to the methodology used, namely, theoretical (a priori) research, then analytical research, and finally empirical research. In the subsequent section, we respond to the main questions of the Discussion Paper.

\section{Prior research}

\subsection{Theoretical (a priori) research}

Theoretical (a priori) research uses logical arguments and conceptual thinking to derive solutions to a problem, based on normative theory. In the following, we discuss two themes that are related to the themes in the Discussion Paper.

The Discussion Paper is based on the asset-liability model that is favoured by the boards. While this model does have some merits, the alternative revenue-expense model that was the conceptual basis of accounting standards for many decades also has merits. Dichev (2008) lists three of them: (i) The revenue-expense model follows the underlying business process of earnings generation and reflects business reality; (ii) conceptually, income determination is clearer and more useful than assets and liabilities; and (iii) earnings is the most important output of the accounting system. In a long-term empirical analysis Dichev and Tang (2008) find that the increased use of the asset-liability model in the U.S. had negative effects on the quality of accounting earnings.

Despite the emphasis on the asset-liability model, the revenue recognition concept in the Discussion Paper is mixed and includes elements of a revenue-expense model. For example, the proposed relative stand-alone price allocation of the contract transaction price is an allocation (of the difference between stand-alone prices and the contract price) rather than an individual measurement of the respective performance obligations or any group of such obligations. A similar observation holds for the continuous recognition of, say, a warranty obligation (as discussed in paragraph A28 of the Discussion Paper), which is another allocation.

There are alternative revenue recognition concepts that have not been discussed in the Discussion Paper. For example, Wüstemann and Kierzek (2005) propose an asset and liability transaction approach that is derived from an appeal to the legal existence of the entity's right of obtaining consideration. They suggest that "revenue should be recognized when the enterprise obtains the right to consideration in exchange for the substantive fulfilment of its 
performance obligation” (Wüstemann and Kierzek, 2005, p. 95). The difference to the proposed revenue recognition model in the Discussion Paper is based on the satisfaction of performance obligations is gradual and based on legal claims rather than on economic criteria. Wüstemann and Kierzek (2007) discuss their approach for construction contracts and Wüstemann and Kierzek (2008) for service contracts. In many cases, their approach would imply later revenue recognition than under the Discussion Paper's model.

However, Nobes (2006) and Alexander (2006) argue against Wüstemann and Kierzek in support of an approach that is more similar to the Discussion Paper. A PAAinE (2007) Discussion Paper favors a continuous approach in contrast to a critical events approach taken by the Discussion Paper.

We conclude that the revenue recognition approach in the Discussion Paper attempts to achieve conceptual consistency, and it clearly increases consistency relative to the existing set of standards. However, the literature casts some doubt that their appeal to the asset-liability model as the consistent concept is the best way to regulate revenue recognition.

\subsection{Analytical research}

Analytical research stresses the fact that accounting provides additional information for specific purposes. Revenue recognition rules influence the information content in the accounting system (see, e.g., Christensen and Demski, 2003, particularly Chapter 14; Liang, 2001). In essence, revenue recognition rules determine the timing when new information is recorded in the accounting system. Most of the literature deals with stewardship issues and potential welfare effects of early or late recognition for that objective. ${ }^{2}$ Accounting systems aggregate individual information into earnings, which makes it difficult or impossible to disentangle the individual information, and reduces the comparability of the information produced by applying different methods. It is not surprising that most of the literature finds ambiguous results about the preferability of certain revenue recognition methods, thus, opposing the idea of a single consistent concept that is the best for all situations.

Antle and Demski (1989) study revenue recognition from an information (consumption smoothing of risk averse agents) and a stewardship (providing incentives to agents) perspective. They show that the preferability of early or late recognition depends on the time in which the risk of the outcome of the production process is resolved. The situation becomes more complicated if earnings management is considered as well (see Christensen and Demski,

\footnotetext{
${ }^{2}$ We note that the IASB tends to focus on decision usefulness and to consider stewardship objectives as secondary (see the Exposure Draft of An Improved Conceptual Framework for Financial Reporting - Chapter 1: The Objective of Financial Reporting, Chapter 2: Qualitative Characteristics and Constraints of Decision-useful Financial Reporting Information from May 2008).
} 
2003, Chapter 14). Antle and Demski stress the trade-offs that are incurred and that prohibit an easy solution to any revenue recognition discussion.

Liang (2000) examines a setting in which the manager is privately informed. Revenue recognition partially conveys that private information at different times. He shows that recognition is most useful at the time when the moral hazard problem is most critical (and not, e.g., at the time when the most uncertain event takes place). If the manager can self-report the private information, late recognition is preferable because it can be more effectively used to control earnings management incentives.

Glover (2004) sketches a model that examines how a robust revenue recognition standard would look like in a setting similar to those of Antle and Demski (1989) and Liang (2004). If the owners and the manager do not know exactly the governing probability distributions, earlier recognition can be superior to late recognition.

Liang and Zhang (2006) find that flexible revenue recognition rules can be preferable to stringent rules because their choice can convey additional information about the quality of the underlying information about the earnings process. However, if the incentives for earnings management are strong, stringent rules may become more desirable.

The Discussion Paper does include some rules that require judgment, e.g., the identification of performance obligations and their measurement. The literature suggests that leaving some discretion on the recognition of revenue to management does not necessarily have a negative effect but can carry additional information. However, it is difficult to describe in more general terms, as standards do, the settings in which such a benefit is likely to obtain.

Dutta and Zhang (2002) consider a multi-period agency model in which in each period a manager receives information about the production environment and makes productive decisions. They examine how goods that are produced in one period and sold in a subsequent period should be measured to provide optimal incentives to the manager. Although, formally, they do not study contracts with customers because they assume the selling price is uncertain, their analysis is still interesting also for contracts. If revenue is realized only when the goods are sold a residual-income based contract achieves optimal incentives, whereas revenue recognition based on the market price of the goods fails to provide effective incentives. The reason is that the market price anticipates the manager's future performance and, thus, does not provide incentives to deliver that performance. Moreover, the market price aggregates future cash flows differently from what would be optimal for performance evaluation. Dutta and Zhang, thus, show that the accounting for decision usefulness and for stewardship can differ significantly.

Dutta and Reichelstein (2005) study accounting rules for multi-period construction contracts with the objective to find goal-congruent performance measures. Goal congruence aligns the performance measure with the owners' value maximization objective, independent of possible 
differences in their time horizons, discount rate, and structure of the compensation function. Thus, the performance measure must reflect value generation in each period. Obviously, the completed-contract method does not satisfy this criterion because it recognizes revenue only in the period of the completion of the contract, thus biasing the performance measures in all periods. The percentage-of-completion method does better, but also does not achieve goal congruence because it does not include the effects of discounting, which is fundamental to value generation (based on the net present value). Dutta and Reichelstein develop a so-called present-value-percentage-of-completion method that eliminates the time inconsistency and achieves goal congruence.

Mohnen and Bareket (2007) consider a setting in which a manager must rank different projects according to their value generation. They show that any goal-congruent performance measure must include a revenue recognition rule that differs from cash flows. The revenue recognition must be such that it effectively annuitizes the net present value of a project.

Several studies compare the completed-contract and percentage-of-completion methods for construction contracts in an agency setting where accounting information is used as a performance measure for a manager's compensation. The models typically consider a twoperiod setting in which the percentage-of-completion method includes some information from the second period already in the first-period earnings. However, since the performance measure aggregates different pieces of information, the contract cannot make use of these pieces individually, hence, the two methods provide information that is not directly comparable.

Hofmann (2005) shows that without the possibility of the renegotiation of the compensation contract of the manager, the percentage-of-completion method dominates the completedcontract method because the percentage-of-completion method provides more information in the early period. However, under renegotiation too much information in early periods can be detrimental for the renegotiation phase because the information can be used to fine-tune the second-period contract, which is anticipated by the manager who adjusts the first-period effort. Hofmann shows that the preferability of the two methods depends on how much information the first-period earnings provide about the second period. Schöndube (2008) studies a similar setting but considers unverifiable information. He finds that if long-term activities are more important than short-term activities, the percentage-of-completion method dominates the completed-contract method.

Arnegger and Hofmann (2007) study the optimal allocation base for the percentage-ofcompletion method in a situation without renegotiation. They find that input- and outputbased measures for the degree of completion are rarely optimal; the optimal allocation base depends on the productivity of the agent and the risk in the periods of construction. 
Dobler (2008) argues that the percentage-of-completion method gives more relevant information, while the completed-contract leads to more reliable information. For performance measurement, completed-contract has the effect of providing negative incentives for starting construction contracts, as managers must recognize losses, but not gains. In this sense, Dobler argues that percentage-of-completion is more neutral, but at the cost of a higher opportunity for earnings management.

Although the models focus on a variety of economic effects, they generally support the percentage-of-completion method over the completed-contract method for long-term contracts. If the revenue recognition criteria suggested in the Discussion Paper lead to an increase in the use of the completed-contract method, e.g., in the construction industry, the effects may be negative. However, earnings management opportunities are greater under the percentage-of-completion method and should be considered as well.

\subsection{Empirical research}

In this section we cover empirical literature related to revenue recognition. There are several strains of research covered. We start with accounting choice, i.e., how reporting entities tend to make choices on reporting revenue in different situations and what factors may determine these choices. Next, we survey studies on the quality of accounting information, in which the focus shifts from the producers to the users of financial statements. The last part of this section covers miscellaneous issues, such as how accounting standards should be written.

Starting with accounting choice, there are several studies that have focused on internet and other IT companies. This is because many issues in reporting revenue have been especially important in this industry. Many new accounting pronouncements pertaining to this industry have been issued, especially in the US. Both Altamuro et al (2005) and Srivastava (2008) study the effects of new accounting pronouncements that decreased discretion in reporting revenues. While Altamuro et al found a reduction in earnings management following the new pronouncement, Srivastava identified no such effect. Both studies indicate a decrease in usefulness of revenue numbers after the introduction of less discretion. Bowen et al (2002) find that earnings management is stronger for internet firms with higher cash burn rate (indicating a high need for external financing). Chamberlain (2002), however, suggests caution in interpreting these results.

Besides the studies that focus on internet and the IT industry, there are some more general studies on accounting choice. Larson and Brown (2004) show that there is diversity in practice for reporting revenue on long-term contracts, suggesting the need for stricter regulation. Marquardt and Wiedman (2004) study in what situations different income statement items are used for earnings management. They find that revenues are accelerated especially for firms that are in the process of issuing equity. Choi (2007) shows that firms that are more dependent on banks tend to recognise losses earlier (i.e., exhibit more conservative 
accounting), which also leads to an increase in value relevance of the income statement. Nelson et al (2003) show that revenue is a financial statement item that is subject to substantial earnings management.

Next, we focus on research on the quality of accounting, i.e., how different ways of reporting revenue affects the quality of accounting. Zhang (2004) studies the adoption of new regulation for the software industry reporting of revenues, and finds that a lower level of discretion leads to an increase in the timeliness and relevance of reported revenue, but reduces the reliability and time-series predictability. Cerf (1975) argues that discretion in reporting revenues relating to long-term contracts is positive and improves the quality of accounting. The same argument is made by Baker and Hayes (2004) relating to the Enron case.

These findings suggest that allowing more discretion in revenue recognition should be avoided, although the literature is not unanimous on the issue because the effects may be context-dependent. In industries with stronger incentives (such as the IT industry, where public offerings may cause strong incentives and high pressure for growth) stricter accounting standards appear advantageous. In construction, an industry characterized by a higher longterm stability (albeit cyclical variation), more discretion may be useful. These observations suggest that a uniform and consistent revenue recognition model may be inferior to industryspecific revenue recognition rules.

Apart from the debate on the level of discretion, there is a host of papers that cover other quality issues. Barley (1995) suggests a probability-based model that would yield better results than a model based on transfer of control. Samuelson (1993) shows that the transaction price is not a good basis for the measurement of performance obligations. Based on a similar reasoning, Friedman (1978) suggests that an entire income statement based on exit prices is preferable. Davis (2002) focuses on internet firms and finds that firms that report grossed-up or barter revenue exhibit a lower value relevance of earnings. Ball and Shivakumar (2006) find that an asymmetric recognition of losses is relevant. In an earlier study, however, Ball and Shivakumar (2005) show that the quality of early loss recognition depends on the market context of reporting entities.

It is probably difficult to directly apply these studies in practice. What we can conclude, however, is that it could be relevant to recognize unrealized losses earlier than gains, which is similar to what the boards suggest for onerous contracts.

Another effect from revenue recognition comes from deferred taxes. Guenther and Sansing (2000) study the effect of differences in financial reporting and tax for income statement items, including revenue. They find that such differences can affect the quality of accounting, an issue that may be especially relevant in Europe, where there is a multitude of tax regimes. Any revenue recognition accounting standard promulgated by the IASB is likely to differ from revenue recognized for tax purposes in many jurisdictions. Even though the IASB does 
not (and should not) consider local tax regulation, Guenther and Sansing's findings imply that the magnitude of financial reporting and tax differences could have an impact on the quality of accounting.

Other studies focus on how users treat accounting information related to revenue. In an experimental study, Trotman and Zimmer (1986) find that subjects are functionally fixated and, generally, do not make adjustments for alternative revenue recognition methods when analyzing financial statements. This evidence suggests that (contrary to findings we discuss above) having a single, consistent model of revenue recognition for all transactions is useful. It can be expected to lead to similar transactions being treated in a similar manner, regardless of in which circumstance the transaction occurs, which is an advantage for functionally fixated investors.

Prakash and Sinha (2009) argue that standards that require deferring the recognition of revenue, but the corresponding expenses are not deferred, e.g., because those expenses include a large portion of general indirect costs, introduce a mismatch of revenues and expenses. They find that if changes in deferred revenues in two periods are significant, investors and analysts have difficulty in forecasting future profit margins, so that analysts' forecast errors increase and prices do not fully incorporate the implications of the changes in deferred revenues. They attribute their findings to the increased complexity of predicting future performance. Since the Discussion Paper does not alter the matching of costs, such negative consequences are likely to continue to exist.

A different issue is studied by Clor-Proell and Nelson (2007), namely, how accounting standards should be written. They find that producers of accounting base their interpretation of standards on examples rather than the text per se. Thus, standard-setters should provide relevant examples, especially for areas that are conceptually new. This would particularly apply to the Discussion Paper on revenue recognition.

\section{Response to the main questions}

We organize our responses to the questions in the Discussion Paper along the fundamental issues addressed in the research surveyed.

One question is whether it is preferable to have a single revenue recognition principle that is based on the entity's contract asset or liability. From the research it is not obvious that the asset-liability model dominates the revenue-expense model, as the Discussion Paper claims. Moreover, it is not obvious if inconsistencies (e.g., those in existing standards) are really undesirable. There may well exist a higher-level principle the seemingly inconsistent revenue recognition rules obey or could obey. In addition, the proposal to net the liability arising from the performance obligation and the right for consideration is an aggregation of information, which inevitably destroys information that may be useful. Finally, empirical research suggests 
that financial reporting is contingent on the situation, in that information based on a certain principle may be more or less useful in different situations. Together, this research suggests a need for a diversity of approaches to revenue recognition.

Another question is concerned with the satisfaction of performance obligations. We note that the legal enforcement of seemingly similar claims for consideration may differ across jurisdictions. It is not obvious whether the economic substance or the legal existence of a claim is the better criterion for revenue recognition to produce decision-useful information.

A fundamental (and open) question is the measurement of performance obligations. The Discussion Paper includes two approaches, the transaction price approach and the current exit price approach. Analytical research suggests that the transaction price approach has benefits (at least for performance evaluation) over the current exit price approach, which includes more market risk or more judgment. Moreover, recognizing day-1 gains and losses as in the current exit price anticipates future performance, which can be detrimental to providing incentives for management to perform. Empirical research suggests that early recognition of losses of onerous performance obligations provides useful information. Also, research suggests that a more timely recognition of bad news than good news is a desirable characteristic of financial reporting.

A further question is the allocation of the transaction price to the performance obligations and the fact that contract origination costs are not included in performance obligations. Such ancillary costs are expensed when they occur rather than allocated to the performance obligations they help to generate. Analytical research suggests that all costs should be matched to the revenues they relate to, in order to mitigate incentives for sub-optimal management decisions and, thus, to serve the stewardship objective. However, a mismatch of revenues and costs recognition may impede the predictability of earnings.

A more general question relates to the level of discretion in revenue recognition provided to reporting entities. Research suggests that discretion can be beneficial as a means of providing information. To the extent that discretion increases with the principles suggested in the Discussion Paper, this would have a benefit. The allocation of transaction price to different performance obligations may be an example.

Research indicates a functional fixation in the interpretation of revenue related transactions. Then the control model may not be optimal from a user perspective, especially as it pertains to constructions contracts. If the control model results in revenue recognized when a contract is completed, it would be difficult for financial reporting users to see through to the economic substance of the transaction. 


\section{Literature}

Alexander, D. (2006): Legal Certainty, European-ness and Realpolitik, Accounting in Europe 3, 65-80.

Altamuro, J., A.L. Beatty and J. Weber (2005): The Effects of Accelerated Revenue Recognition on Earnings Management and Earnings Informativeness: Evidence from SEC Staff Accounting Bulletin No. 101, The Accounting Review 80, 373-401.

Antle, R., and J.S. Demski (1989): Revenue Recognition, Contemporary Accounting Research 5, 423-451.

Arnegger, M., and C. Hofmann (2007): Periodisierung von Erfolgskomponenten zur Steuerung langfristiger Aufträge, Zeitschrift für Betriebswirtschaft 77, 115-139.

Baker, C.R., and R. Hayes (2004): Reflecting Form over Substance: The Case of Enron Corp, Critical Perspectives on Accounting 15, 767-785.

Ball, R., and L. Shivakumar (2005): Earnings Quality in UK Private Firms: Comparative Loss Recognition Timeliness, Journal of Accounting \& Economics 39, 83-128.

Ball, R., and L. Shivakumar (2006): The Role of Accruals in Asymmetrically Timely Gain and Loss Recognition, Journal of Accounting Research 44, 207-242.

Barley, B. (1995): Determining the Stage at which It Is Appropriate to Recognize Profit Under Long-Term Contracts, Journal of Business Finance \& Accounting 22, 713-731.

Bowen, R.M., A.K. Davis and S. Rajgopal (2002): Determinants of Revenue-Reporting Practices for Internet Firms, Contemporary Accounting Research 19, 523-562.

Cerf, A.R. (1975): Accounting for Retail Land Sales, The Accounting Review, 451-465.

Chamberlain, S. (2002): Discussion of „Determinants of Revenue-Reporting Practices for Internet Firms“, Contemporary Accounting Research 19, 563-572.

Choi, W. (2007): Bank Relationships and the Value Relevance oft he Income Statement: Evidence from Income-Statement Conservatism, Journal of Business Finance \& Accounting 34, 1051-1072.

Christensen, J.A., and J.S. Demski (2003): Accounting Theory - An Information Content Perspective, McGraw-Hill: Bosten et al.

Clor-Proell, S., and M.W. Nelson (2007): Accounting Standards, Implementation Guidance, and Example-Based Reasoning, Journal of Accounting Research 45, 699-730.

Davis, A.K. (2002): The Value Relevance of Revenue for Internet Firms: Does Reporting Grossed-up or Barter Revenue Make a Difference?, Journal of Accounting Research 40, 445-477.

Dichev, I.D. (2008): On the Balance Sheet-Based Model of Financial Reporting, Accounting Horizons 22, 453-470.

Dichev, I.D., and V.W. Tang (2008): Matching and the Changing Properties of Accounting Earnings over the Last 40 Years, The Accounting Review 83, 1425-1460.

Dobler, M. (2008): Rethinking Revenue Recognition - The Case of Construction Contracts Under International Financial Reporting Standards, International Journal of Revenue Management 2, 1-22.

Dutta, S., and S. Reichelstein (2005): Accrual Accounting for Performance Evaluation, Review of Accounting Studies 10, 527-552. 
Dutta, S., and X.-J. Zhang (2002): Revenue Recognition in a Multiperiod Agency Setting, Journal of Accounting Research 40, 67-83.

Friedman, L.A. (1978): An Exit-Price Income Statement, The Accounting Review 53, 18-30.

Glover, J. (2004): Discussion - A Model of Auditing Under Bright-Line Accounting Standards, Journal of Accounting, Auditing, and Finance 19, 561-564.

Guenther, D.A., and R.C. Sansing (2000): Valuation of the Firm in the Presence of Temporary Book-Tax Differences: The Role of Deferred Tax Assets and Liabilities, The Accounting Review 75, 1-12.

Hofmann, C. (2005): Gestaltung von Erfolgsrechnungen zur Steuerung langfristiger Projekte, Zeitschrift für betriebswirtschaftliche Forschung 57, 689-716.

Larson, R.K., and K.L. Brown (2004): Where Are We with Long-Term Contract Accounting?, Accounting Horizons 18, 207-219.

Liang, P.J. (2000): Accounting Recognition, Moral Hazard, and Communication, Contemporary Accounting Research 17, 457-490.

Liang, P.J. (2001): Recognition: An Information Content Perspective, Accounting Horizons $15,223-242$.

Liang, P.J., and X.-J. Zhang (2006): Accounting Treatment of Inherent versus Incentive Uncertainties and the Capital Structure of the Firm, Journal of Accounting Research 44, 145-176.

Marquardt, C.A., and C.I. Wiedman (2004): How Are Earnings Managed? An Examination of Specific Accruals, Contemporary Accounting Research 21, 461-491.

Mohnen, A., and M. Bareket (2007): Performance measurement for investment decisions under capital constraints, Review of Accounting Studies 12, 1-22.

Nelson, M.W., J.A. Elliot, and R.L. Tarpley (2003): How Are Earnings Managed? Examples from Auditors, Accounting Horizons (Supplement), 17-35.

Nobes, C. (2006): Revenue Recognition and EU Endorsement of IFRS, Accounting in Europe 3, 81-89.

PAAinE (2007): Revenue Recognition - A European Contribution, July.

Prakash, R., and N. Sinha (2009): Deferred Revenues and the Matching of Revenues and Expenses, Working Paper, College of William and Mary, and Boston University.

Samuelson, R.A. (1993): Accounting for Liabilities to Perform Services, Accounting Horizons 7, 32-45.

Schöndube, J.R. (2008): Early Versus Late Effort in Dynamic Agencies with Unverifiable Information, Business Research 1, 165-186.

Srivastava, A. (2008): Do Firms Use Flexibility in Revenue-Recognition Rules to Convey Value-Relevant Information or to Manage Earnings? Working Paper, Texas A\&M University.

Trotman, K.T., and I.R. Zimmer (1986): Revenue Recognition in the Construction Industry: An Experimental Study, Abacus 22, 136-147.

Wüstemann, J., and S. Kierzek (2005): Revenue Recognition under IFRS Revisited: Conceptual Models, Current Proposals and Practical Consequences, Accounting in Europe 3, 69-106. 
Wüstemann, J., and S. Kierzek (2007): Normative Bilanztheorie und Grundsätze ordnungsmäßiger Gewinnrealisierung für Mehrkomponentenverträge, Zeitschrift für betriebswirtschaftliche Forschung 59, 882-913.

Wüstemann, J., and S. Kierzek (2008): Betriebswirtschaftliche Bilanzrechtsforschung und Grundsätze ordnungsmäßiger Gewinnrealisierung für Werkverträge, Zeitschrift für Betriebswirtschaft 79, 31-58.

Zhang, Y. (2004): Revenue Recognition Timing and Attributes of Reported Revenue: The Case of Software Industry's Adoption of SOP 91-1, Journal of Accounting and Economics 39, 535-561. 